\title{
Jorge Sahade: First Latin American IAU President
}

\author{
Lydia S. Cidale \\ Instituto de Astrofísica de La Plata, CONICET-UNLP, and \\ Facultad de Ciencias Astronómicas y Geofísicas, Universidad Nacional de La Plata, \\ Paseo del Bosque S/N, La Plata, Argentina \\ email: lydia@f caglp.unlp.edu.ar
}

\begin{abstract}
Prof. Jorge Sahade (1915-2012) was the first Latin American President of the International Astronomical Union (1985-1988). From then on, he had a very active participation as president, vice-president, and organizing committee member of several Commissions and Divisions of the IAU, related to stellar astrophysics and exchange of astronomers. Prof. J. Sahade was born in Argentina and was one of the first students graduated in astronomy at the National University of La Plata. He served as director of the Astronomical Observatory of Córdoba (1953-1955) and of the Observatory of La Plata (1968-1969). He was the first Dean of the Faculty of Exact Sciences of the National University of La Plata. He promoted the purchase of a 2.15-m diameter telescope, today located in the Complejo Astronómico El Leoncito, San Juan, Argentina. He founded the Institute of Astronomy and Physics of Space (IAFE) in Buenos Aires and was its first director (1971-1974). He was also director of the "Comisión Nacional de Actividades Espaciales" (the Argentina Space Activity Agency) and promoted the inclusion of Argentina as a partnership of the Gemini Observatory. Prof. Sahade also focused on the development of the astronomy in Latin America and this led to the creation of the "Liga Latinoamericana de Astronomía" (nowadays LIADA).

His research field was interacting binary systems and he published about 150 papers, among them is the well-known discovery of the "Struve-Sahade effect". I met him when he was 70 years old; he was a very enthusiastic astronomer, who travellled everywhere to promote the astronomy in Latin America (Argentina, Perú, Honduras). Among his last dreams was the creation of a Latin American Institute to develop and enhance astrophysics in South and Central America, the revival of UV astronomy and many more impressive works that he would have liked to end and publish.
\end{abstract}

Keywords. Jorge Sahade, astronomy in Latin America, presidency of the IAU

\section{Introduction}

I first met Prof. Dr Jorge Sahade in 1985, the year he became the first Latin American President (1985-1988) of the International Astronomical Union (IAU), during the appearance of Halley's comet. At that time, I was an undergraduate student in astronomy at the National University of La Plata, Argentina. I went to the Department of Stellar Spectroscopy to start developing my thesis with Dr Adela Ringuelet, Prof. Sahade's wife. I remembered whispers, anxiety, enthusiasm and some stir among Sahade's research group related to the trip to India (the IAU meeting in New Delhi). At that moment little did I know about the IAU or the real relevance of Prof. Sahade for Argentine and worldwide astronomy.

A year later, thanks to his efforts and tireless conviction, a major milestone was reached. Our most important astronomical facility, the 2.15-m telescope, 


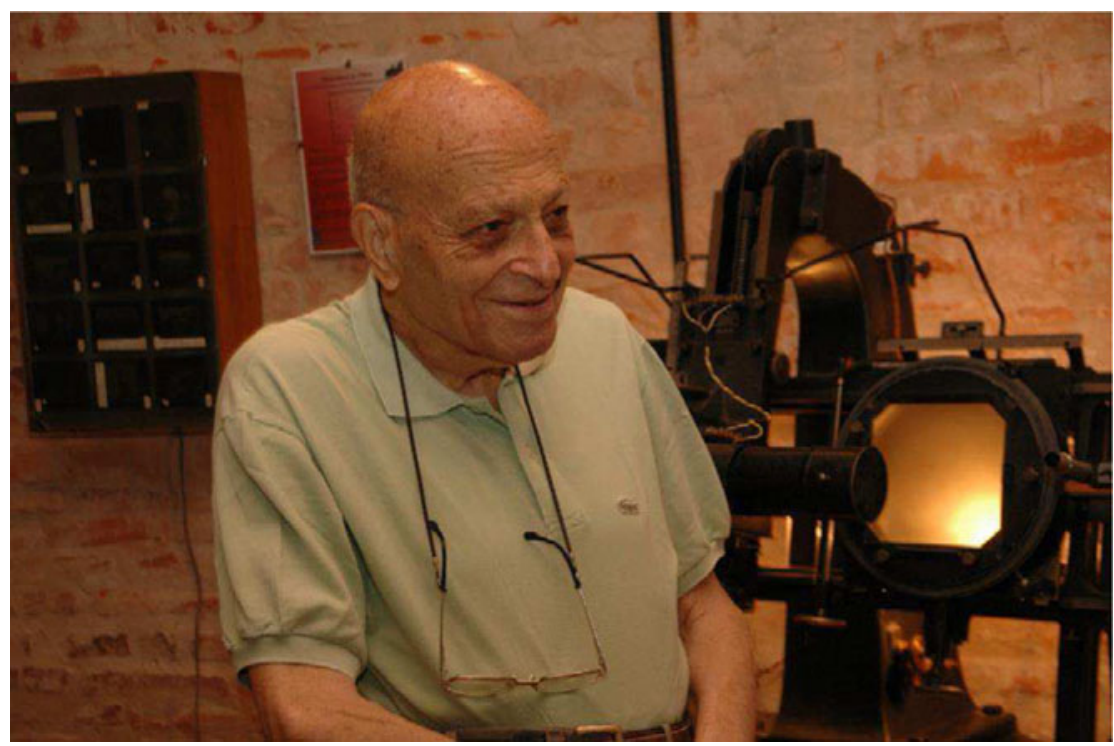

Figure 1. Prof. Jorge Sahade in the museum of the Faculty of Astronomical and Geophysical Sciences of the National University of La Plata, Argentina.

named "Jorge Sahade Telescope" was inaugurated at the Complejo Astronómico El Leoncito (CASLEO), San Juan, Argentina.

During the next few years, I occasionally met with Dr Sahade, who quietly entered the office, said hello, and asked about the development of two papers I had been invited to work on as co-author. As always, he asked seriously "Do you think that astronomy would be better if you do this?". Trembling, ..., I did not have an answer to that haunting question.

Little by little, I began to discover who that mysterious and tenacious astronomer was, whose spiritual bearing still stands tall, and whose life is an example to us (Fig. 1). I had the pleasure to share with him, between teacups and meetings, many wonderful talks and to hear exciting stories about himself and his journeys. Not less interesting were the stories about world-famous astronomers and the history of astronomy in the middle of unstable times for the economy and politics of our country.

\section{Who was Jorge Sahade?}

Dr Jorge Sahade was born in a small town, named Alta Gracia, in Córdoba, Argentina, on February 17, 1915. He was mainly interested in studying mathematics, but in his native province the course of study that best suited his wishes was civil engineering at the University of Córboba. However, at one point he decided to abandon engineering and to take up land surveying. The year after his graduation (1938), he moved to Buenos Aires (Argentina) to get a position at the Military Geographic Institute. There he learned about the career in astronomy that was taught at the Observatory of La Plata since 1934, and the University of La Plata was offering the courses free of charge to promote this course of study. Thus, this was the first Higher School of Astronomy and Related Sciences in Latin America. The first students who registered were Carlos Cesco and Guillermina Martín joining, then, Gualberto Iannini, Alba Schreiber and, in 1938, J. Sahade. Part of Sahade's previous studies were recognized and finally, three years later, he was the third graduate student in astronomy. Details of his biography can be found in Sahade (2009, 2006); DeVorkin (1997). 
By that time, Ing. Felix Aguilar was director of the Observatory of La Plata and he was greatly interested in promoting astrophysics as a new research field in Argentina. His aspiration was so strong that in 1941, when J. Sahade was appointed as Assistant Astronomer at the Observatory, the director asked Sahade which field of Astronomy he would like to work in. Sahade replied enthusiastically that he liked Celestial Mechanics and, suddenly, he was told that he would work with Dr Wilkens in Astrophysics.

J. Sahade obtained his Ph.D degree in astronomy in mid-1943 and director Ing. Felix Aguilar granted him together with C. Cesco two scholarships for two years to study and conduct research under the direction of the most distinguished stellar spectroscopists of the twentieth century, Prof. Otto Struve, who was Director of the Yerkes and McDonald Observatories. In Yerkes, on two occasions, he worked with who was later awarded the Nobel Prize in Physics, namely Dr Subrahmanyan Chandrasekhar, and met many more astronomers who are now famous, like W.W. Morgan, G. Kuiper, J. Greenstein and L. Henyey.

In February 1946, Dr J. Sahade returned to Argentina and joined the staff of the Observatory of Córdoba. This staff would be later on enlarged by other graduates from La Plata: G. Iannini, J.L. Sérsic and L. Milone. After the 1.5-m telescope was finally inaugurated in Bosque Alegre (Córdoba), the team began to study the Magellanic Clouds and to perform systematic works of stellar spectroscopy and, particularly, eclipsing binaries.

J. Sahade was director of the Astronomical Observatory of Córdoba (1953-1955), and in 1955, he moved from Córdoba to the Department of Astronomy in Berkeley (University of California), with a scholarship of the Guggenheim Foundation, to work again with Dr O. Struve until June 1958. That same year, back in Argentina, Prof. Sahade played a key role in the foundation and regulation of the Argentine Astronomy Association and promoted the creation of our National Committee of Astronomy in charge of linking our country with the IAU (Sahade 2006). He served as President of the Argentine Astronomy Association (1963-1969). He also concentrated all his efforts towards the consolidation of a broader collaboration within the Latin American astronomical community and promoted the creation of the Liga Latinoamericana de Astronomía (nowadays LIADA), of which he was one of its first-day honorary members.

Shortly after arriving in Argentina, Dr C. Cesco, who was Director of the Observatory of Córdoba, commissioned Dr J. Sahade to carry out the project to provide the University of La Plata with a modern large reflector telescope. Seriously determined to accomplish the task entrusted to him, he wrote to the most important astronomers of different countries from Europe and the United States to know how much support he could find abroad. Particularly generous was Dr Nicholas Mayall, Director of the Kitt Peak National Observatory in Tucson, Arizona, who offered him, completely free of charge, the drawings to build a twin instrument of the Kitt Peak telescope. The telescope was purchased with a loan from the Inter-American Development Bank, but the political and economic oscillations of our country delayed its inauguration for about 20 years. Without the tenacity and perseverance of J. Sahade, the creation of CASLEO would not have been possible (Fig. 2).

In 1959, Director Cesco also asked Sahade to organize an international meeting. Sahade decided to hold in La Plata a symposium on Stellar Evolution, where Otto Struve, Allan Sandage, the Burbidge spouses, Margaret and Geoffrey, Maarten Schmidt, Halton Arp, George Herbig, Olin Eggen, Leon Mestel, Guillermo Haro attended, all of them among the most outstanding astronomers in the world (Fig. 3).

During his tenure as Director of the Observatory of La Plata between 1968 and 1969, and later as Dean of the Faculty of Exact Sciences (1969), he came to the conclusion that our universities did not realize that they were living in a new era, "the space age" and it was necessary to create a modern Institute. In 1971, CONICET approved the foundation 


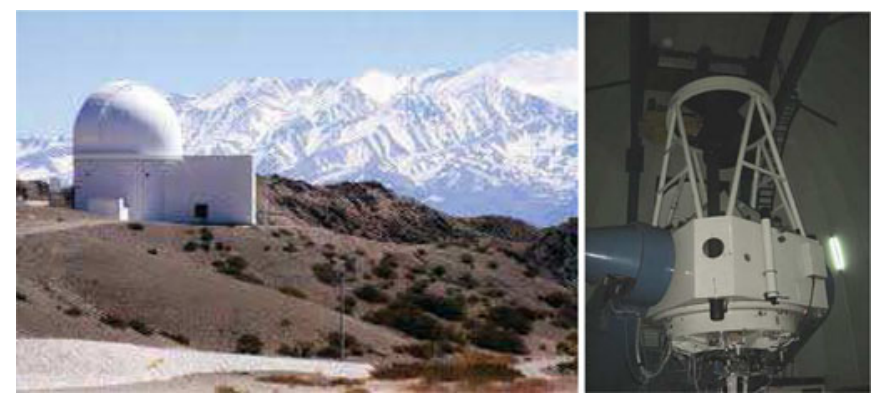

Figure 2. Left: The Complejo Astronómico El Leoncito, San Juan, Argentina. Right: the $2.15 \mathrm{~m}$ Jorge Sahade telescope.
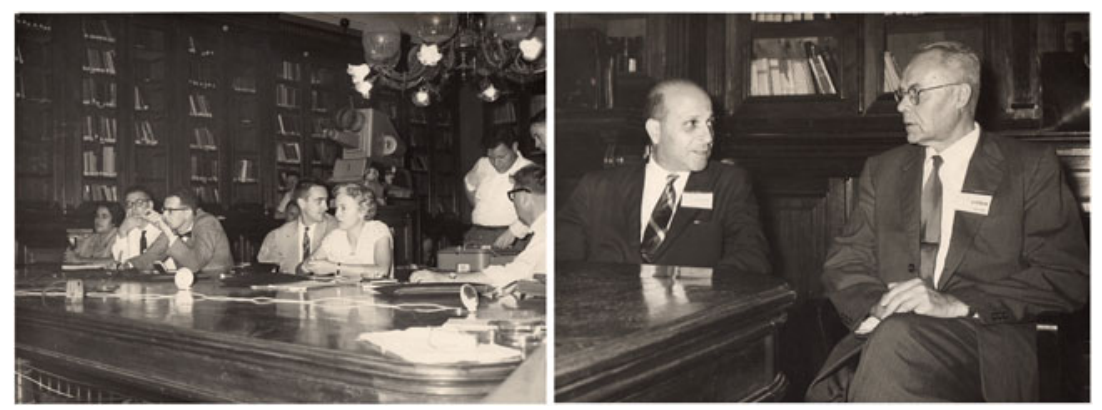

Figure 3. Symposium on Stellar Evolution, held in La Plata 1960 (left panel), from left to right: Mercedes Corvalán-Jaschek, Carlos Jaschek, Maarten Schmidt, Carlos Hernández, Friedman Herbert, W. Wilkens, Halton Arp, Margaret Peachey Burbidge, José Luis Sérsic, Olin Eggen and Alejandro Feinstein. J. Sahade and O. Struve (right panel).

of the Institute of Astronomy and Physics of Space (IAFE), in Buenos Aires, based on the original plan drawn up by Sahade, Sérsic and Ghielmetti. The IAFE emerged as a pioneer institute in experiments in cosmic radiation, in gamma, $\mathrm{X}$, and infra-red rays, with a strong observational profile, taking great advantage of technological developments carried out in the country. J. Sahade was the first director (1971-1974) of that institution. He was also director of the Argentine National Space Activity Agency (Comisión Nacional de Actividades Espaciales, CONAE) and promoted the inclusion of Argentina as a partnership of the Gemini Observatory, which consists of twin 8.2-m telescopes, where he was a board member in 1995. More recently, CONICET created the Institute of Astrophysics of La Plata (IALP), by merging two programmes, one led by Dr A. Feinstein and the other by J. Sahade. During a brief period, the IALP management was shared by both programme leaders.

\section{Sahade's scientific contributions and international activities}

During his career, J. Sahade published about 150 peer-reviewed papers and around 200 paper contributions. His research field was interacting binary systems. Among his main scientific contributions is the well-known discovery of the "Struve-Sahade effect" (S-S effect). This effect occurs in a double-lined spectroscopic binary star system when the strength of the spectral lines varies during the orbital motion. These lines become anomalously weaker as a star spectrum is red-shifted, and stronger when it is blue-shifted, most noticeable in the secondary component. Sahade also studied many other binary star systems that may be related to $\epsilon$ Aurigae and proposed for the first time the possibility that the secondary star can be more massive than the primary (Sahade et al. 1959). 
He also studied symbiotic stars and Wolf-Rayet stars, many of them observed by the International Ultraviolet Explorer (IUE).

Dr J. Sahade had a deep concern and involvement in the IAU's affairs and problems. He served as President (1985-1988) and Vice-president (1967-1970, 1970-1973, 1982-1985) of the Executive Committee, President of Commission 29 Stellar Spectra (1964-1967) and Commission 38 Exchange of Astronomers (1991-1994), and actively participated as a member of Commission 29 Stellar Spectra; Commission 30 Radial Velocities; Commission 38 Exchange of Astronomers; Commission 42 Close Binary Stars; Commission 44 Space \& High Energy Astrophysics; Commission 46 Astronomy Education \& Development; Division IV Stars; Division V Variable Stars; Division XI Space \& High Energy Astrophysics; Division XII Union-Wide Activities, until December 2012, when he passed away. Details on his past affiliations within the IAU can be found in the web-site www.iau.org/administration/membership/individual/2266.

As president of the IAU, he created the Working Group for the Promotion and Development of Astronomy to foster the astronomy in less-developed countries. Moreover, he encouraged Argentinian astronomers to organize the XXI General Assembly of the IAU in Buenos Aires (1991), that being the first time that a General Assembly was held in South America. He expected that the General Assembly would help to promote a collaboration in astronomy among Latin American countries and would be a great opportunity to secure support for astronomical development locally. For several years, he was a strong advocate of Latin American integration in astronomy, and worked for the establishment of a Latin American Institute, although these dreams never came to fruition.

The roots of contemporary astronomy in Perú can be traced directly to the past IAU President Jorge Sahade, in the frame of Visiting Lecturers Projects, when he started the first courses in September 1984. He also boosted the teaching and growth of astronomy in Honduras, where he gave many lectures even when he was 90 years old. In tribute, the conference room of the Observatorio Astronómico Centroamericano de Suyapa of the University of Honduras bears his name.

Over his career, J. Sahade received many awards and acknowledgments: Konex Prize for Physics and Astronomy (1983); Asteroid 2605 (1974QA) bears the name of Sahade (1986); Medal of Scientific Consecration (in Astronomy) of the Council of Advanced International Studies (1988); Ricardo P. Platzeck Prize in Astronomy, National Academy of Exact, Physical and Natural Sciences (1993); Researcher Emeritus of CONICET (1995); Gold Medal of the Argentina Friends of Astronomy Association (1999); Citizen Illustrious of the City of La Plata (2011).

And every three years, the Argentine Astronomy Association grants the Jorge Sahade Award for Scientific Trajectory.

\section{Anecdotes and Reflections}

From time to time, I used to visit him at an old people's home. One day, when he was 95 years old, he said "As soon as I get better, I'll go back to the Observatory, there are still several works that I would like to publish". And, particularly, several months later, I heard his most amazing story, when he told me "Do you know, I had never been interested in astronomy before I went to La Plata; I started my studies because of curiosity and I found out that astronomy was fantastic". Then, he remembered "When I was born it seems that my mother did not have much faith, she thought that I would not survive many days, she saw me very weak - he laughed a lot - that's why my parents registered me on February 23th, instead of on 17th, the day I was born."

The pursuit of scientific results was not the only thing in which Dr Sahade showed his tenacity. He always encouraged everyone to explore new results and was committed 
to getting to the astronomical community with everything he could offer. Undoubtedly, astronomy was his passion.

For his activity he received several awards but, particularly, the Asteroid 2605 (1974QA), named Sahade, will intrigue and instruct future generations to wonder who this great astronomer was. I hope we can be as persevering and determined as he was to move forward and grow.

\section{References}

Sahade, J., Huang, S. S, Struve, O \& Zebergs, V. 2009, American Philosophical Society, Vol. 49, p. 32

Sahade, J. 2006, Boletín de la Asociación Argentina de Astronomía, Vol. 49, p. 391

Sahade, J. 2009, in: G. E. Romero, S. A. Cellone \& S. A. Cora (eds.), Asociación Argentina de Astronomía BOOK SERIES, Vol. 2, p. 43

DeVorkin, D. 1997, in: Interview of Jorge Sahade by David DeVorkin on 1997 August 24, Niels Bohr Library \& Archives, American Institute of Physics, College Park, MD USA, www.aip.org/history-programs/niels-bohr-library/oral-histories/33325 